\title{
Androgen deprivation therapy-associated vasomotor symptoms
}

\author{
Jason M Jones, Manish Kohli and Charles L Loprinzi
}

Androgen deprivation therapy (ADT) is widely used as standard therapy in the treatment of locally advanced and metastatic prostate cancer. While efficacious, ADT is associated with multiple side effects, including decreased libido, erectile dysfunction, diabetes, loss of muscle tone and altered body composition, osteoporosis, lipid changes, memory loss, gynecomastia and hot flashes. The breadth of literature for the treatment of hot flashes is much smaller in men than that in women. While hormonal therapy of hot flashes has been shown to be effective, multiple non-hormonal medications and treatment methods have also been developed. This article reviews current options for the treatment of hot flashes in patients taking ADT.

Asian Journal of Andrology (2012) 14, 193-197; doi:10.1038/aja.2011.101; published online 30 January 2012

Keywords: androgen deprivation therapy; hot flashes; vasomotor symptoms

\section{INTRODUCTION}

Prostate cancer is the most common cancer diagnosed in men in the United States with an estimated 217730 new cases in 2010. ${ }^{1}$ Androgen deprivation therapy (ADT) has become part of standard therapy for locally advanced as well as metastatic disease, with approximately $40 \%$ of patients with prostate cancer receiving ADT within 6 months of diagnosis. ${ }^{2}$ Furthermore, the estimated prevalence of prostate cancer in the United States is 2.355 million cases, of which more than onethird will have received ADT at some time point of their disease course. ${ }^{3}$ While this therapy can be quite efficacious, it, concomitantly, is associated with a number of side effects, due to both androgen and estrogen deficiencies, including decreased libido and erectile dysfunction, diabetes, loss of muscle tone, altered body composition, osteoporosis, lipid changes, memory loss, gynecomastia and hot flashes. Up to $80 \%$ of patients on ADT experience hot flashes, which occurs both with surgical castration (bilateral orchiectomy) or medical castration in the form of leuteinizing hormone releasing hormone analogs. ${ }^{4,5}$ The symptoms of hot flashes in men were reported as early as 1941 by Huggins and Hodges ${ }^{6}$ in 9 of the first 21 prostate cancer patients ever to undergo ADT.

Hot flashes are defined as an intense heat sensation, flushing and diaphoresis that usually involve the face and trunk. Associated symptoms may include anxiety and palpitations. Episodes often occur repeatedly and usually last for a few to several minutes, but can persist for up to $20 \mathrm{~min}$. Many patients only report mild consequences from their symptoms and only experience these sporadically. However, some patients experience multiple hot flashes each day and report significant effect on daily functioning and quality of life. Definitions of hot flash severities in men with ADT have been previously published. ${ }^{7}$

\section{HOT FLUSHES IN WOMEN VERSUS MEN}

Despite the clinical significance of ADT-associated hot flashes in men, the treatment of this problem has remained relatively overlooked in medical literature. This is likely because hot flushes have predominantly been considered a symptom more commonly associated with females.

Nonetheless, it has been suggested that hot flushes are mostly sex neutral and the treatment approaches seen in women apply to both sexes. ${ }^{8}$ This contention is, first, supported by examining the etiology of hot flashes in each of these cases. Hot flashes in women have been classically described at the onset of menopause, a time of an abrupt decrease in estrogen; hot flashes often dissipate in 2-5 years, but may persist for $10-15$ or more years. In addition, they are commonly associated with other states of estrogen withdrawal, including oophorectomy and anti-estrogenic medications used for the treatment of breast cancer. Likewise, hot flashes develop in males who have had acute withdrawal of sex hormones such as in the use of ADT. These symptoms usually persist as long as the duration of the therapy. ${ }^{9}$ It has been speculated that estrogen and androgen withdrawal disrupts the equilibrium of the neurotransmitters, norepinephrine and serotonin. This in turn disrupts the homeostatic mechanism in the thermoregulatory zone in the pre-optic zone of the hypothalamus. ${ }^{10}$ These neurotransmitters have become targets for developing non-hormonal treatments for hot flashes.

As will be discussed in more details below, when similar treatment was been studied in both men and women, similar efficacy has usually been seen. ${ }^{8,11-17}$

Thus, at this time, recommendations for the treatment of ADTinduced hot flashes can be drawn from a combination of data from randomized trials conducted in men as well as from randomized trials

Department of Medical Oncology, Mayo Clinic, Rochester, MN 55905, USA 
of some agents in women with supporting pilot trail data regarding the same agents in men.

\section{HORMONAL TREATMENTS}

\section{Estrogen}

For years, estrogen therapy has been used and has been shown to be very effective for the treatment of hot flashes in women. Likewise, despite estrogen not being approved by the USA Federal Drug Administration for this use, estrogen therapy in men has also been found to be quite efficacious. Multiple small prospective trials, employing low-dose diethylstilbestrol, have resulted in over $70 \%$ of men having a complete resolution of hot flashes. ${ }^{18-20}$ Diethylstilbestrol has been used at dose of $1 \mathrm{mg}$ daily, which has been shown to be strong enough to remedy hot flashes, and has not been associated with as much of an increased incidence of thromboembolic or cardiovascular events as are seen with higher doses of this drug. A pilot study of a transdermal estrogen patch at two different doses resulted in improvement of symptoms in $83 \%$ of the participants, with moderate to major improvement observed in $67 \%$ of the study population at the higher dose. ${ }^{21}$ Treatment was, however, complicated by dose-dependent gynecomastia. A subsequent trial examined the use of a transdermal estrogen patch in androgen-independent prostate carcinoma. Patients with hot flashes at baseline had a $77 \%$ reduction in hot flashes. Grade 2 gynecomastia and gynecodynia were seen in $17 \%$ of patients. No increase of thromboembolic events was observed. Therefore, estrogen can be used as a highly effective agent in the treatment of hot flashes given at the doses listed in Table 1, but with associated toxicities.

\section{Progesterone analogs}

Megestrol acetate is a kind of progesterone analog shown to be beneficial for the treatment of hot flashes. A double-blind, randomized study, involving women with breast cancer and men with prostate cancer who were enrolled to receive $40 \mathrm{mg} \mathrm{d}^{-1}$ versus a placebo, was conducted. Patients on active treatment had a $75 \%-80 \%$ reduction in hot flashes, ${ }^{15}$ which was equivalent in men and women. Long-term follow-up of the same patient population supported sustained benefit in men and women who continued for 3 years or more. ${ }^{22}$ In another double-blind, randomized trial in women, a megestrol acetate dose of $20 \mathrm{mg} \mathrm{d}^{-1}$ appeared to be equivalent to $40 \mathrm{mg} \mathrm{d}^{-1}$. $^{23}$

Data in women support that the alternative progesterone analog, medroxyprogesterone acetate, is equally effective for treating hot flashes in women. ${ }^{24} \mathrm{~A}$ retrospective analysis also suggested that parenteral medroxyprogesterone was also effective in men with $91 \%$ symptomatic improvement. ${ }^{25} \mathrm{~A}$ randomized trial, involving men with ADT-associated hot flashes, compared medroxyprogesterone and venlafaxine, revealing a greater hot flash reduction in the medroxyprogesterone arm than was seen in the venlafaxine arm. ${ }^{16}$ These results are similar to what has been seen in a randomized trial in women with hot flashes, comparing medroxyprogesterone acetate and venlafaxine. ${ }^{17}$

While progesterone analogs, such as megestrol acetate, have been used, at times, to treat prostate cancer, there are data that support that, at times, it can actually increase prostate cancer growth. ${ }^{26,27}$ This may occur for similar reasons as to why prostate cancer growth can occur with other hormonal modifying agents used to treat prostate cancer, such as bicalutamide. Similar to what is done in the case of bicalutamide, consideration of stopping progesterone therapy should occur in patients with evidence of prostate cancer growth.

\section{Cyproterone acetate}

Cyproterone acetate, a hormonal agent used in Europe for the treatment of prostate cancer, was also compared to medroxyprogesterone acetate and venlafaxine. ${ }^{16}$ It appeared to decrease hot flashes to a similar degree as medroxyprogesterone acetate and more that what was observed with venlafaxine. Cyproterone acetate, however, is not approved for use in the United States.

\section{GABAPENTIN AND PREGABALIN}

Gabapentin has traditionally been used as an anticonvulsant and for treatment of neuropathic pain. Over the past decade, it has also become a non-hormonal alternative for the treatment of hot flashes. Gabapentin has become one of the most studied non-hormonal agents for the treatment of hot flashes in men.

Table 1 Hot flash treatment options

\begin{tabular}{|c|c|c|c|}
\hline Drug & Dose & Expected reduction in hot flashes & Most common toxicities \\
\hline \multicolumn{4}{|l|}{ Hormonal agents } \\
\hline Diethylstibestrol (DES) $)^{\mathrm{a}, 18-20}$ & $1 \mathrm{mg} \mathrm{d}^{-1} \mathrm{PO}$ & $70 \%-90 \%$ & Gynecomastia, gynecodynia \\
\hline Estradiol $^{b, 21}$ & 0.05 mg transdermal weekly & $70 \%-90 \%$ & Gynecomastia, gynecodynia \\
\hline Megestrol acetate ${ }^{a, 15,23}$ & $20-40 \mathrm{mg} \mathrm{d}^{-1} \mathrm{PO}$ & $70 \%-90 \%$ & Bloating, weight gain, thrombogenic \\
\hline Medroxyprogesterone $e^{\mathrm{a}, 16,17}$ & 400 mg IM single dose (repeat for relapse) & $70 \%-90 \%$ & Bloating, thrombogenic \\
\hline Cyproterone acetate ${ }^{\mathrm{a}, 16}$ & $100 \mathrm{mg} \mathrm{d}^{-1} \mathrm{PO}$ & $70 \%-90 \%$ & Fatigue, weakness \\
\hline \multicolumn{4}{|l|}{ Non-hormonal agents } \\
\hline \multicolumn{4}{|l|}{ Anti-seizure agents } \\
\hline Gabapentin ${ }^{\mathrm{a}, 12}$ & $300 \mathrm{mg} \mathrm{d}^{-1}$ PO thrice daily & $50 \%-60 \%$ & Dizziness, fatigue, somnolence \\
\hline Pregabalin c,11,13,14,31 & 75 mg PO twice daily & $50 \%-60 \%$ & Cognitive difficulty, sleepiness, weight gain \\
\hline \multicolumn{4}{|l|}{ Antidepressants } \\
\hline Venlafaxine $e^{c, 16,17,34}$ & $75 \mathrm{mg} \mathrm{d}^{-1}$ extended release PO daily & $50 \%-60 \%$ & Anorexia, dry mouth, insomnia, nausea \\
\hline Desvenlafaxine $e^{c, 40,41}$ & $100 \mathrm{mg} \mathrm{d}^{-1}$ PO daily & $50 \%-60 \%$ & Dizziness, nausea, vomiting \\
\hline Paroxetine $e^{c, 37,38}$ & $10 \mathrm{mg} \mathrm{d}^{-1}$ controlled release PO daily & $50 \%-60 \%$ & Insomnia, nausea, sexual dysfunction \\
\hline Citalopram ${ }^{c, 39,67}$ & 10-20 $\mathrm{mg} \mathrm{d}^{-1}$ PO daily & $50 \%-60 \%$ & Constipation, dry mouth, nausea \\
\hline Fluoxetine ${ }^{c, 36,67}$ & $20 \mathrm{mg} \mathrm{d}^{-1} \mathrm{PO}$ daily & $30 \%-50 \%$ & Dry mouth \\
\hline
\end{tabular}

Abbreviations: IM, intramuscularly; PO, orally taken.

${ }^{a}$ Randomized controlled data in men.

${ }^{b}$ Pilot data in men.

${ }^{\mathrm{c}}$ Randomized controlled data, but only from trials conducted in women. 
Pursuant to a case report series of gabapentin being effective for the treatment of hot flashes involving five women and one man, ${ }^{28}$ a pilot study was performed, revealing a $66 \%$ reduction in hot flashes in women at a target dose of $900 \mathrm{mg}$ in three equally divided doses. ${ }^{29}$ Multiple subsequent randomized placebo-controlled trials showed significant hot flash reductions in women. ${ }^{11,13,14}$

A large randomized trial was performed in men with prostate cancer on ADT, whereby 214 patients were equally divided to receive placebo, or target doses of 300,600 or $900 \mathrm{mg} \mathrm{d}^{-1} .{ }^{12}$ There were reductions in hot flash scores by $22 \%, 23 \%, 32 \%$, and $46 \%$ in the four study arms, respectively. An open labeled continuation of the study was then performed, which allowed all four patients arms to be titrated up to $900 \mathrm{mg} \mathrm{d}^{-1}$. This resulted in an improvement in hot flash control in the placebo and lower dose arms, to a similar degree as was seen in the higher dose arm of the randomized portion of this trial. ${ }^{30}$ The data from this trial are quite comparable to the data derived from the randomized gabapentin trials in women with hot flashes. Gabapentin was not associated with increased toxicity when compared with placebo. However, gabapentin has been associated with a number of side effects including nausea, vomiting, dizziness and somnolence.

Pregabalin, a gabapentin analog, has also been studied for the treatment of hot flashes in women. This was done via a double-blind, placebo-controlled randomized trial which enrolled 163 patients to receive placebo, or target pregabalin doses of $150 \mathrm{mg} \mathrm{d}^{-1}$ versus $300 \mathrm{mg} \mathrm{d}^{-1} \cdot{ }^{31}$ Patients receiving pregabalin had significant reductions of hot flashes in comparison to placebo, to a similar degree as had been observed with gabapentin. ${ }^{11,13,14}$ There was no treatment difference between the two doses, in terms of hot flash reductions, but more dizziness and cognitive impairment occurred in those receiving the higher dose. No trials have been performed in men regarding the utility of pregabalin for treating ADT-associated hot flashes.

Based on these data, gabapentin is a reasonable therapy to recommend for the treatment of ADT-induced hot flashes with a starting dose at $300 \mathrm{mg}$ daily titrated at increments of $300 \mathrm{mg}$ in order to achieve a dose of $900 \mathrm{mg} \mathrm{d}^{-1}$ divided in three equal doses. Alternatively, for men primarily suffering from night sweats, a bedtime dose of 100-300 mg, with further titration of the bedtime dose to $900 \mathrm{mg} \mathrm{d}^{-1}$, can be considered. Presumably, pregabalin would also be an option, as data in women show that it reduces hot flashes, ${ }^{31}$ accepting that this drug has not been specifically tested in men. For pregabalin, it is reasonable to start at an initial dose of $75 \mathrm{mg} \mathrm{d}^{-1}$ and increase it to a target dose of $75 \mathrm{mg}$ twice daily.

\section{NEWER ANTIDEPRESSANTS}

It was anecdotally observed, in the 1990s, that some women on antidepressant therapy had fewer hot flashes than those not taking the medication. Therefore, pilot trials were performed employing venlafaxine, a serotonin-norepinephrine reuptake inhibitor, and paroxetine, a selective serotonin reuptake inhibitory. ${ }^{32,33}$ These agents were shown to be effective for reducing hot flashes in women in subsequent randomized trials, as have a number of other antidepressants. $^{34-41}$

An initial pilot study of venlafaxine, reported in 1998, enrolled women with breast cancer as well as men on ADT. The patients reported a $55 \%$ reduction in hot flashes as well as improvement in fatigue, diaphoresis and difficulty sleeping. ${ }^{32}$ Expanded experience, involving 16 men, showed similar results with a $54 \%$ reduction in median hot flash score after 4 weeks. ${ }^{42}$ A follow-up double-blinded, placebo-controlled randomized clinical trial in women demonstrated that venlafaxine decreased hot flashes by about $60 \%$, compared to a placebo reduction of $27 \% .{ }^{34} \mathrm{~A}$ recent randomized trial comparing venlafaxine, medroxyprogesterone acetate and cyproterone acetate in men on ADT, supported the initial observation of the pilot trial, with a $47 \%$ reduction in hot flash score. Of note, hormonal therapy with medroxyprogesterone and cyproterone had a significantly larger benefit in this trial, than did venlafaxine, similar to the comparison of medroxyprogesterone acetate with venlafaxine in women. ${ }^{17}$

Two pilot studies, evaluating paroxetine, have been performed in men undergoing ADT. The first enrolled 24 men to receive an initial dose of $12.5 \mathrm{mg} \mathrm{d}^{-1}$. This was increased to $25 \mathrm{mg} \mathrm{d}^{-1}$ at week 3 and further increased to $37.5 \mathrm{mg}$ at week 4 . The population experienced a reduction from 6.2 hot flashes daily to 2.3 daily, by the end of the trial. ${ }^{43}$ A later pilot study from Japan studied 10 patients. After baseline collection, the patients were given $10 \mathrm{mg} \mathrm{d}^{-1}$. This resulted in a reduction in daily hot flashes from 3.5 to $2 .^{44}$

Pilot data, published in 1998, suggested that sertraline may be able to treat hot flashes in men undergoing ADT. ${ }^{45}$ However, multiple randomized placebo-controlled trials in women have suggested that this drug is not as helpful for treating hot flashes as are some other antidepressants. ${ }^{35}$

Thus, while no placebo-controlled, randomized trials have been performed to date in men to evaluate the utility of newer antidepressants for alleviating ADT-associated hot flashes, it does appear reasonable to consider the use of this therapy in men. This recommendation is based on the notations that (i) the pilot study data in men have provided similar data to what was observed in pilot trials in women; (ii) that multiple double-blind, placebo-controlled, randomized trials in women have demonstrated that these drugs decrease hot flashes; and (iii) that most data support that things that work in women, also work in men. Having said this, it is also reasonable for informed physicians and patients to opt not to try these medications, given that they have not been proven to be helpful.

Specific drugs and doses are provided in Table 1. Side effects are generally mild and consist of dry mouth, nausea and decreased appetite. Gastrointestinal side effects typically resolve after 1-2 weeks of treatment. Based on suggestive data in women that another antidepressant may be helpful when one is not, ${ }^{46}$ it is reasonable to try an alternative antidepressant when another one does not appear to be helping. A trial of antidepressants in controlling or preventing hot flashes, however, will need to take into account the potential for drug interactions with newer hormonal agents used in the treatment of prostate cancer in future, including abiraterone acetate, which is an inhibitor of CYP 2D6. Co-administration of abiraterone with CYP 2D6 substrates including several antidepressants have a narrow therapeutic index and should be avoided, or require, at the very minimum, a dose reduction of the CYP 2D6 substrates.

\section{CLONIDINE}

Clonidine is a centrally acting alpha adrenergic antagonist that initially was suggested to have benefit for the treatment of hot flashes in the 1970s. ${ }^{47-49}$ A randomized trial was performed enrolling women with a history of breast cancer and showed a significant improvement in hot flashes. However, the side effects were felt to outweigh the benefits and clonidine was not recommended for treatment. ${ }^{50}$ Despite the effectiveness in women, a large randomized trial did not show benefit for transdermal clonidine in men. ${ }^{51}$ The reason for the different results remains unclear. Therefore, clonidine is not recommended for the treatment of hot flashes in men. 


\section{VITAMIN E}

The only randomized control studies thus far have been performed in women. ${ }^{52}$ In addition, there is recent data that suggests vitamin E may increase the risk of prostate cancer, making this a less desirable treatment for men with prostate cancer. ${ }^{53}$

\section{BEHAVIORAL MODIFICATIONS}

A reasonable initial approach to any patient with hot flashes is behavioral modifications. While research has been relatively limited, modifications such as use of a fan, wearing loose fitting clothing, sipping cold drinks and lowering room temperature have minimal detrimental effect and, in fact, may make symptoms tolerable. ${ }^{54}$ Additional things that have been recommended for women by the North American Menopausal Society include dietary modifications including the limitation of spicy foods. ${ }^{55}$

\section{ACUPUNCTURE}

Acupuncture has been used in Eastern medicine for thousands of years and has shown benefit against chemotherapy-induced nausea and vomiting, as well as chronic pain. ${ }^{56}$ Starting in the late 1990 s, trials were performed to examine the effectiveness of acupuncture for the treatment of hot flashes. An obvious obstacle is the difficulty of blinding and providing a placebo. Sham procedures, which consist of 'incorrectly placed' needles, have been performed, but there are concerns regarding the validity of these controls. In addition, acupuncture is a procedure and likely differs with experience of the practitioner. At this time, there are not convincing evidence that acupuncture is helpful for treating hot flashes in women. ${ }^{57,58}$

Two pilot studies have been performed in men with prostate cancer on ADT. The first enrolled seven patients and showed a 50\% reduction in hot flashes after 3 months. ${ }^{59}$ A more recent pilot study of 22 patients also suggested benefit with $55 \%$ of patients having a reduction in more than half of hot flash symptoms. ${ }^{60}$ However, a systematic review concluded that there is not enough evidence to recommend acupuncture as an efficacious therapy for hot flashes in men. This is the only systematic review using exclusively male patients, but it only includes five observational studies and one randomized trial that did not use a sham procedure. $^{61}$

\section{OTHER NON-PHARMACOLOGICAL TREATMENTS}

Some other non-pharmacological therapies are currently being studied. Potential treatments include hypnosis, ${ }^{62}$ paced breathing/ yoga and stellate ganglion block. ${ }^{63-66}$ Most of these have shown promise in pilot studies in women, but have not been studied in men with ADT-associated hot flashes. More information and evidence examining use of these methods of therapy will hopefully become available over the next several years.

\section{CONCLUSION}

ADT-associated hot flashes are frequent and can be very disruptive for many men undergoing ADT. There are reasonable data to support that those both hormonal and non-hormonal agents can effectively diminish ADT-induced hot flashes. While non-hormonal agents appear to be less effective at decreasing these hot flashes than are hormonal agents, they have less ability to interfere with the ADT that the patient is receiving and may, thus, be worth trying first. Gabapentin is the best studied one of these non-hormonal agents in men, but the efficacy of pregabalin and multiple antidepressants (Table 1), probably have similar efficacy.
Hormonal therapy options include estrogenic drugs, progesterone analogs and cyproterone acetate. Our own bias, if a hormonal agent is desired to treat ADT-induced hot flashes, is to use one of the progesterone analogs, e.g., megestrol acetate $\left(20-40 \mathrm{mg} \mathrm{d}^{-1}\right.$ orally) or medroxyprogesterone acetate $\left(20 \mathrm{mg} \mathrm{d}^{-1}\right.$ orally or a one-time intramuscular dose of $400 \mathrm{mg}$, with consideration of retreatment in subsequent weeks or months if hot flashes relapse). Such therapy should be preceded by a thorough discussion of the potential for prostate cancer growth.

The body of evidence for the treatment of hot flashes has grown extensively over the past two decades and new and hopefully more effective treatments will be discovered in the near future.

\section{COMPETING FINANCIAL INTERESTS}

All authors declare that there are no competing financial interests.

1 Jemal A, Siegel R, Xu J, Ward E. Cancer statistics, 2010. CA Cancer J Clin 2010; 60: 277-300.

2 Shahinian VB, Kuo YF, Gilbert SM. Reimbursement policy and androgen-deprivation therapy for prostate cancer. N Engl J Med 2011; 363: 1822-32.

3 SEER Stat Fact Sheets: Prostate. Bethesda, MD: National Cancer Institute; 2010.

4 Guise TA, Oefelein MG, Eastham JA, Cookson MS, Higano CS et al. Estrogenic side effects of androgen deprivation therapy. Rev Urol 2007; 9: 163-80.

5 Thompson CA, Shanafelt TD, Loprinzi CL. Andropause: symptom management for prostate cancer patients treated with hormonal ablation. Oncologist 2003; 8: 474-87.

6 Huggins C, Hodges C. Studies on prosate cancer. Effect of castration, estrogen, and adrogen injection on serum phosphatases in metastatic carcinoma of the prostate. Cancer Res 1941; 1: 293-7.

7 Quella S, Loprinzi CL, Dose AM. A qualitative approach to defining "hot flashes" in men. Urol Nurs 1994; 14: 155-8.

8 Loprinzi CL, Sherry L. Hot flushes: mostly sex neutral? Lancet Oncol 2010; 11: 107-8.

9 Karling $\mathrm{P}$, Hammar M, Varenhorst E. Prevalence and duration of hot flushes after surgical or medical castration in men with prostatic carcinoma. J Urol 1994; 152: 1170-3.

10 Shanafelt TD, Barton DL, Adjei AA, Loprinzi CL. Pathophysiology and treatment of hot flashes. Mayo Clin Proc 2002; 77: 1207-18.

11 Guttuso T Jr, Kurlan R, McDermott MP, Kieburtz K. Gabapentin's effects on hot flashes in postmenopausal women: a randomized controlled trial. Obstet Gynecol 2003; 101: 337-45.

12 Loprinzi CL, Dueck AC, Khoyratty BS, Barton DL, Jafar S et al. A phase III randomized, double-blind, placebo-controlled trial of gabapentin in the management of hot flashes in men (NOOCB). Ann Oncol 2009; 20: 542-9.

13 Pandya KJ, Morrow GR, Roscoe JA, Zhao H, Hickok JT et al. Gabapentin for hot flashes in 420 women with breast cancer: a randomised double-blind placebo-controlled trial. Lancet 2005; 366: 818-24.

14 Reddy SY, Warner H, Guttuso T Jr, Messing S, Digrazio W et al. Gabapentin, estrogen, and placebo for treating hot flushes: a randomized controlled trial. Obstet Gynecol 2006; 108: 41-8.

15 Loprinzi CL, Michalak JC, Quella SK, O'Fallon JR, Hatfield AK et al. Megestrol acetate for the prevention of hot flashes. N Engl J Med 1994; 331: 347-52.

16 Irani J, Salomon L, Oba R, Bouchard P, Mottet N. Efficacy of venlafaxine, medroxyprogesterone acetate, and cyproterone acetate for the treatment of vasomotor hot flushes in men taking gonadotropin-releasing hormone analogues for prostate cancer: a double-blind, randomised trial. Lancet Oncol 2010; 11: 147-54.

17 Loprinzi CL, Levitt R, Barton D, Sloan JA, Dakhil SR et al. Phase III comparison of depomedroxyprogesterone acetate to venlafaxine for managing hot flashes: North Central Cancer Treatment Group Trial N99C7. J Clin Oncol 2006; 24: 1409-14.

18 Atala A, Amin M, Harty JI. Diethylstilbestrol in treatment of postorchiectomy vasomotor symptoms and its relationship with serum follicle-stimulating hormone, luteinizing hormone, and testosterone. Urology 1992; 39: 108-10.

19 Miller JI, Ahmann FR. Treatment of castration-induced menopausal symptoms with low dose diethylstilbestrol in men with advanced prostate cancer. Urology 1992; 40: 499-502.

20 Smith JA Jr. A prospective comparison of treatments for symptomatic hot flushes following endocrine therapy for carcinoma of the prostate. J Urol 1994; 152: 132-4.

21 Gerber GS, Zagaja GP, Ray PS, Rukstalis DB. Transdermal estrogen in the treatment of hot flushes in men with prostate cancer. Urology 2000; 55: 97-101.

22 Quella SK, Loprinzi CL, Sloan JA, Vaught NL, DeKrey WL et al. Long term use of megestrol acetate by cancer survivors for the treatment of hot flashes. Cancer 1998; 82: 1784-8.

23 Goodwin JW, Green SJ, Moinpour CM, Bearden JD 3rd, Giguere JK et al. Phase III randomized placebo-controlled trial of two doses of megestrol acetate as treatment for menopausal symptoms in women with breast cancer: Southwest Oncology Group Study 9626. J Clin Oncol 2008; 26: 1650-6. 
24 Bertelli G, Venturini M, del Mastro L, Bergaglio M, Sismondi P et al. Intramuscular depot medroxyprogesterone versus oral megestrol for the control of postmenopausal hot flashes in breast cancer patients: a randomized study. Ann Oncol 2002; 13: 883-8.

25 Langenstroer $\mathrm{P}$, Kramer B, Cutting B, Amling C, Poultan T et al. Parenteral medroxyprogesterone for the management of luteinizing hormone releasing hormone induced hot flashes in men with advanced prostate cancer. J Urol 2005; 174: 642-5.

26 Sartor O, Eastham JA. Progressive prostate cancer associated with use of megestrol acetate administered for control of hot flashes. South Med J 1999; 92: 415-6.

27 Burch PA, Loprinzi CL. Prostate-specific antigen decline after withdrawal of low-dose megestrol acetate. J Clin Oncol 1999; 17: 1087-8.

28 Guttuso TJ Jr. Gabapentin's effects on hot flashes and hypothermia. Neurology 2000 54: 2161-3.

29 Loprinzi C, Barton D, Sloan J, Zahasky KM, Smith D et al. Pilot evaluation of gabapentin for treating hot flashes. Mayo Clin Proc 2002; 77: 1155-63.

30 Moraska AR, Atherton PJ, Szydlo DW, Barton DL, Stella PJ et al. Gabapentin for the management of hot flashes in prostate cancer survivors: a longitudinal continuation study-NCCTG Trial NOOCB. J Support Oncol 2010; 8: 128-32.

31 Loprinzi CL, Qin R, Baclueva EP, Flynn KA, Rowland KM Jr et al. Phase III, randomized, double-blind, placebo-controlled evaluation of pregabalin for alleviating hot flashes, N07C1. J Clin Oncol 2009; 28: 641-7.

32 Loprinzi CL, Pisansky TM, Fonseca R, Sloan JA, Zahasky KM et al. Pilot evaluation of venlafaxine hydrochloride for the therapy of hot flashes in cancer survivors. J Clin Oncol 1998; 16: 2377-81.

33 Stearns V, Isaacs C, Rowland J, Crawford J, Ellis MJ et al. A pilot trial assessing the efficacy of paroxetine hydrochloride in controlling hot flashes. Breast Cancer Res Treat 1997; 46: 23-113.

34 Loprinzi CL, Kugler JW, Sloan JA, Mailliard JA, LaVasseur BI et al. Venlafaxine in management of hot flashes in survivors of breast cancer: a randomised controlled trial. Lancet 2000; 356: 2059-63.

35 Loprinzi CL, Sloan J, Stearns V, Slack R, lyengar M et al. Newer antidepressants and gabapentin for hot flashes: an individual patient pooled analysis. J Clin Oncol 2009 27: $2831-7$

36 Loprinzi CL, Sloan JA, Perez EA, Quella SK, Stella PJ et al. Phase III evaluation of fluoxetine for treatment of hot flashes. J Clin Oncol 2002; 20: 1578-83.

37 Stearns V, Beebe KL, lyengar M, Dube E. Paroxetine controlled release in the treatment of menopausal hot flashes: a randomized controlled trial. JAMA 2003 289: 2827-34.

38 Stearns V, Slack R, Greep N, Henry-Tilman R, Osborne M et al. Paroxetine is an effective treatment for hot flashes: results from a prospective randomized clinical trial. J Clin Oncol 2005; 23: 6919-30.

39 Barton DL, LaVasseur BI, Sloan JA, Stawis AN, Flynn KA et al. Phase III, placebocontrolled trial of three doses of citalopram for the treatment of hot flashes: NCCTG trial N05C9. J Clin Oncol 2010; 28: 3278-83.

40 Archer DF, Seidman L, Constantine GD, Pickar JH, Olivier S. A double-blind, randomly assigned, placebo-controlled study of desvenlafaxine efficacy and safety for the treatment of vasomotor symptoms associated with menopause. Am J Obstet Gynecol 2009; 200: 172.e1-10.

41 Speroff L, Gass M, Constantine G, Olivier S. Efficacy and tolerability of desvenlafaxine succinate treatment for menopausal vasomotor symptoms: a randomized controlled trial. Obstet Gynecol 2008; 111: 77-87.

42 Quella SK, Loprinzi CL, Sloan J, Novotny P, Perez EA et al. Pilot evaluation of venlafaxine for the treatment of hot flashes in men undergoing androgen ablation therapy for prostate cancer. J Urol 1999; 162: 98-102.

43 Loprinzi CL, Barton DL, Carpenter LA, Sloan JA, Novotny PJ et al. Pilot evaluation of paroxetine for treating hot flashes in men. Mayo Clin Proc 2004; 79: 1247-51.

44 Naoe M, Ogawa Y, Shichijo T, Fuji K, Fukagai T et al. Pilot evaluation of selec tive serotonin reuptake inhibitor antidepressants in hot flash patients under androgen-deprivation therapy for prostate cancer. Prostate Cancer Prostatic Dis 2006; 9: 275-8.

45 Roth AJ, Scher HI. Sertraline relieves hot flashes secondary to medical castration as treatment of advanced prostate cancer. Psychooncology 1998; 7: 129-32.

46 Carpenter LA, Loprinzi C, Flynn PJ, Atheron P, Barton D et al. Pilot evaluation of citalopram for alleviation of hot flashes in women with inadequate hot flash control with venlafaxine. J Clin Oncol 2005; 23: 8061

47 Clayden JR, Bell JW, Pollard P. Menopausal flushing: double-blind trial of a nonhormonal medication. Br Med J 1974; 1: 409-12.

48 Laufer LR, Erlik Y, Meldrum DR, Judd HL. Effect of clonidine on hot flashes in postmenopausal women. Obstet Gynecol 1982; 60: 583-6.

49 Schindler AE, Muller D, Keller E, Goser R, Runkel F. Studies with clonidine (dixarit) in menopausal women. Arch Gynecol 1979; 227: 341-7.

50 Goldberg RM, Loprinzi CL, O'Fallon JR, Veeder MH, Miser AW et al. Transderma clonidine for ameliorating tamoxifen-induced hot flashes. J Clin Oncol 1994; 12 155-8.

51 Loprinzi CL, Goldberg RM, O'Fallon JR, Quella SK, Miser AW et al. Transderma clonidine for ameliorating post-orchiectomy hot flashes. J Urol 1994; 151: 634-6.

52 Barton DL, Loprinzi CL, Quella SK, Sloan JA, Veeder MH et al. Prospective evaluation of vitamin E for hot flashes in breast cancer survivors. J Clin Oncol 1998; 16: 495500.

53 Klein EA, Thompson IM Jr, Tangen CM, Crowley JJ, Lucia MS et al. Vitamin E and the risk of prostate cancer: the Selenium and Vitamin E Cancer Prevention Trial (SELECT). JAMA 2011; 306: 1549-56.

54 Casper RF, Yen SS. Neuroendocrinology of menopausal flushes: an hypothesis of flush mechanism. Clin Endocrinol (Oxf) 1985; 22: 293-312.

55 North American Menopause S. Treatment of menopause-associated vasomoto symptoms: position statement of The North American Menopause Society. Menopause 2004; 11: 11-33.

56 Conference NC. Acupuncture. JAMA 1998; 280: 1518-24.

57 Vincent A, Barton DL, Mandrekar JN, Cha SS, Zais T et al. Acupuncture for hot flashes: a randomized, sham-controlled clinical study. Menopause 2007; 14: 45-52.

58 Cho SH, Whang WW. Acupuncture for vasomotor menopausal symptoms: a systematic review. Menopause 2009; 16: 1065-73.

59 Hammar M, Frisk J, Grimas O, Hook M, Spetz AC et al. Acupuncture treatment of vasomotor symptoms in men with prostatic carcinoma: a pilot study. J Urol 1999 161: 853-6.

60 Beer TM, Benavides M, Emmons SL, Hayes M, Liu G et al. Acupuncture for hot flashes in patients with prostate cancer. Urology 2010; 76: 1182-8.

61 Lee MS, Kim KH, Shin BC, Choi SM, Ernst E. Acupuncture for treating hot flushes in men with prostate cancer: a systematic review. Support Care Cancer 2009; 17: 763-70.

62 Elkins G, Marcus J, Stearns V, Perfect M, Rajab MH et al. Randomized trial of a hypnosis intervention for treatment of hot flashes among breast cancer survivors. J Clin Oncol 2008; 26: 5022-6.

63 Pachman DR, Barton D, Carns PE, Novotny PJ, Wolf S et al. Pilot evaluation of a stellate ganglion block for the treatment of hot flashes. Support Care Cancer 2011 19: 941-7.

64 Lipov EG, Joshi JR, Sanders S, Wilcox K, Lipov S et al. Effects of stellate-ganglion block on hot flushes and night awakenings in survivors of breast cancer: a pilot study. Lancet Oncol 2008; 9: 523-32.

65 Loprinzi CL, Barton DL, Carns PE. Stellate-ganglion block: a new treatment for hot flushes? Lancet Oncol 2008; 9: 506-7.

66 Lipov E, Lipov S, Stark JT. Stellate ganglion blockade provides relief from menopausa hot flashes: a case report series. J Womens Health (Larchmt) 2005; 14: 737-41.

67 Suvanto-Luukkonen E, Koivunen R, Sundstrom H, Bloigu R, Karjalainen E et al. Citalopram and fluoxetine in the treatment of postmenopausal symptoms: a prospective, randomized, 9-month, placebo-controlled, double-blind study. Menopause 2005; 12: 18-26. 